Feasibility of High-Power Diode Laser Array Surrogate to Support Development of Predictive Laser Lethality Model

W. H. Lowdermilk, A. M. Rubenchik, H. K. Springer

January 24, 2011 
This document was prepared as an account of work sponsored by an agency of the United States government. Neither the United States government nor Lawrence Livermore National Security, LLC, nor any of their employees makes any warranty, expressed or implied, or assumes any legal liability or responsibility for the accuracy, completeness, or usefulness of any information, apparatus, product, or process disclosed, or represents that its use would not infringe privately owned rights. Reference herein to any specific commercial product, process, or service by trade name, trademark, manufacturer, or otherwise does not necessarily constitute or imply its endorsement, recommendation, or favoring by the United States government or Lawrence Livermore National Security, LLC. The views and opinions of authors expressed herein do not necessarily state or reflect those of the United States government or Lawrence Livermore National Security, LLC, and shall not be used for advertising or product endorsement purposes.

This work performed under the auspices of the U.S. Department of Energy by Lawrence Livermore National Laboratory under Contract DE-AC52-07NA27344. 


\title{
Feasibility of High-Power Diode Laser Array Surrogate to Support Development of Predictive Laser Lethality Model
}

\author{
W. H. Lowdermilk, A. M. Rubenchik, H. K. Springer \\ Lawrence Livermore National Laboratory
}

\section{Introduction}

Predictive modeling and simulation of high power laser-target interactions is sufficiently undeveloped that full-scale, field testing is required to assess lethality of military directed-energy (DE) systems. The cost and complexity of such testing programs severely limit the ability to vary and optimize parameters of the interaction. Thus development of advanced simulation tools, validated by experiments under well-controlled and diagnosed laboratory conditions that are able to provide detailed physics insight into the laser-target interaction and reduce requirements for full-scale testing will accelerate development of DE weapon systems. The ultimate goal is a comprehensive end-to-end simulation capability, from targeting and firing the laser system through laser-target interaction and dispersal of target debris; a "Stockpile Science"- like capability for DE weapon systems.

To support development of advanced modeling and simulation tools requires laboratory experiments to generate laser-target interaction data. Until now, to make relevant measurements required construction and operation of vey high power and complex lasers, which are themselves costly and often unique devices, operating in dedicated facilities that don't permit experiments on targets containing energetic materials. High power diode laser arrays, pioneered by $\operatorname{LLNL}^{1,2}$, provide a way to circumvent this limitation, as such arrays capable of delivering irradiances characteristic of DE weapon requirements are self-contained, compact, light weight and thus easily transportable to facilities, such as the High Explosives Applications Facility (HEAF) at Lawrence Livermore National Laboratory (LLNL) where testing with energetic materials can be performed. The purpose of this study was to establish the feasibility of using such arrays to support future development of advanced laser lethality and vulnerability simulation codes through providing data for materials characterization and laser-material interaction models and to validate the accuracy of code predictions. This project was a Feasibility Study under the LLNL Laboratory Directed Research and Development (LDRD) Program.

\section{Experimental Plan}

The purpose of this Feasibility Study was to demonstrate use of a high-power laser diode array to simulate engagement of a solid-fuel rocket by a high-power, anti-missile laser weapon. The goal conceptually, as illustrated by Fig. 1, is to create a surrogate target that reproduces all technically relevant aspects of a threat object, including contained energetic materials such as propellants and explosives, and characterize its response to laser radiation using all appropriate diagnostic instruments under reproducible, well-controlled laboratory conditions. 


\section{Surrogate target - same material, thickness, coatings, stresses, propellant...}

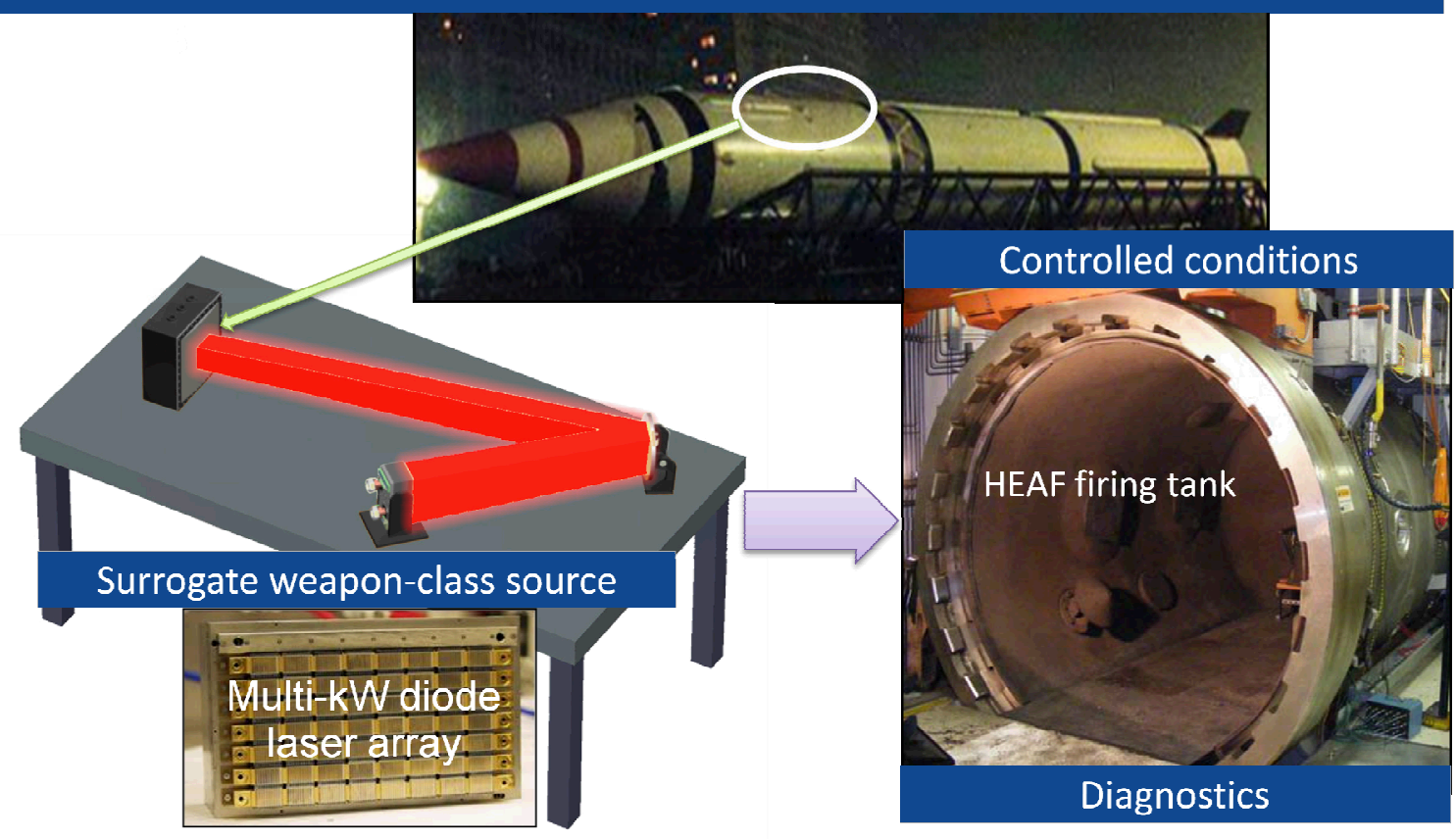

Figure 1. Concept of laboratory lethality experiment with energetic materials

The experimental plan to accomplish this goal consisted of the following tasks.

- Design and build a target canister containing solid-rocket propellant to simulate a solid-fuel rocket

- Determine by 1D thermo-chemical analysis requirements for the diode laser array and light transport system for target irradiation

- Build diode array and light transport system, characterize its transport efficiency, irradiation uniformity and ability to sufficiently heat the target canister to temperatures predictedby the thermo-chemical analysis to achieve ignition of the propellant

- Assemble the test canister and load with propellant

- Install the diode array, test canister, and diagnostic instruments in the HEAF 1-kg firing tank and verify operation

- Conduct experimental measurements using the compact, high-power diode laser array to simulate target irradiation by a DE weapon-class laser on the solid-propellant filled target canister

- Conduct post-shot examination and analysis of the experimental apparatus and diagnostic information, conduct post-shot 2D simulation and compare with observed experimental results. 


\section{Pre-shot Modeling}

The Prout-Tompkins chemical kinetic model was used in ALE3D simulations to estimate the time and temperature to propellant ignition, which is needed to determine the size of the diode array to achieve laser cookoff. This model expresses the mass fraction of unreacted propellant $x$ as

$$
-\frac{d x}{d t}=A \exp \left(-\frac{E}{R T}\right) x^{n}(1-q x)^{m}
$$

where $\mathrm{T}$ is the temperature, $\mathrm{R}$ the gas constant, and $\mathrm{q}$ is commonly written in terms of a parameter $\mathrm{p}$ as

$$
p=-\log _{10}(1-q)
$$

The critical temperature is defined as the point at which the mass fraction equals 1 . Values for the Prout-Tompkins parameters $A, E, m, n$, and $p$ for the RX-62-AX propellant used (powdered ammonium perchlorate (AP) with a $10 \%$ admixture of powdered aluminum), as determined by one-dimensional time-to-explosion measurements ${ }^{3}$ are:

$\ln (A)=19.32, E=42780, m=0.6, n=1$, and $p=3$

The critical temperature was calculated for an applied temperature ramp from $25 \mathrm{C}$ to $650 \mathrm{C}$ in 4,8 , and 12 seconds. Fig. 2 below gives the calculated mass fraction for the 8-second ramp case, which had a critical temperature of $400 \mathrm{C}$.

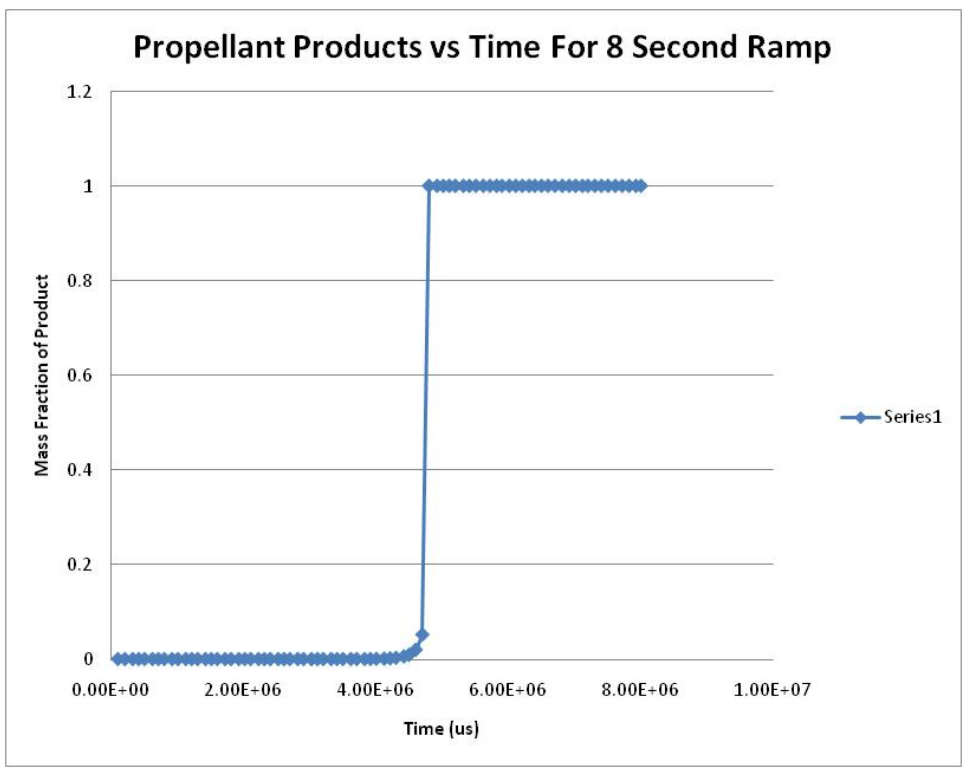

Figure 2 Calculated mass fraction versus time for 8 -sec ramp from $25 \mathrm{C}$ to $650 \mathrm{C}$. 
Similar calculations for the 4-sec. and 12-sec. ramp gave values for the critical temperature of $407 \mathrm{C}$ and $394 \mathrm{C}$ respectively. These results, summarized in Fig. 3, thus show that the critical temperature is nearly independent of the temperature ramp rate in the range of 50 to $150 \mathrm{C} / \mathrm{s}$.

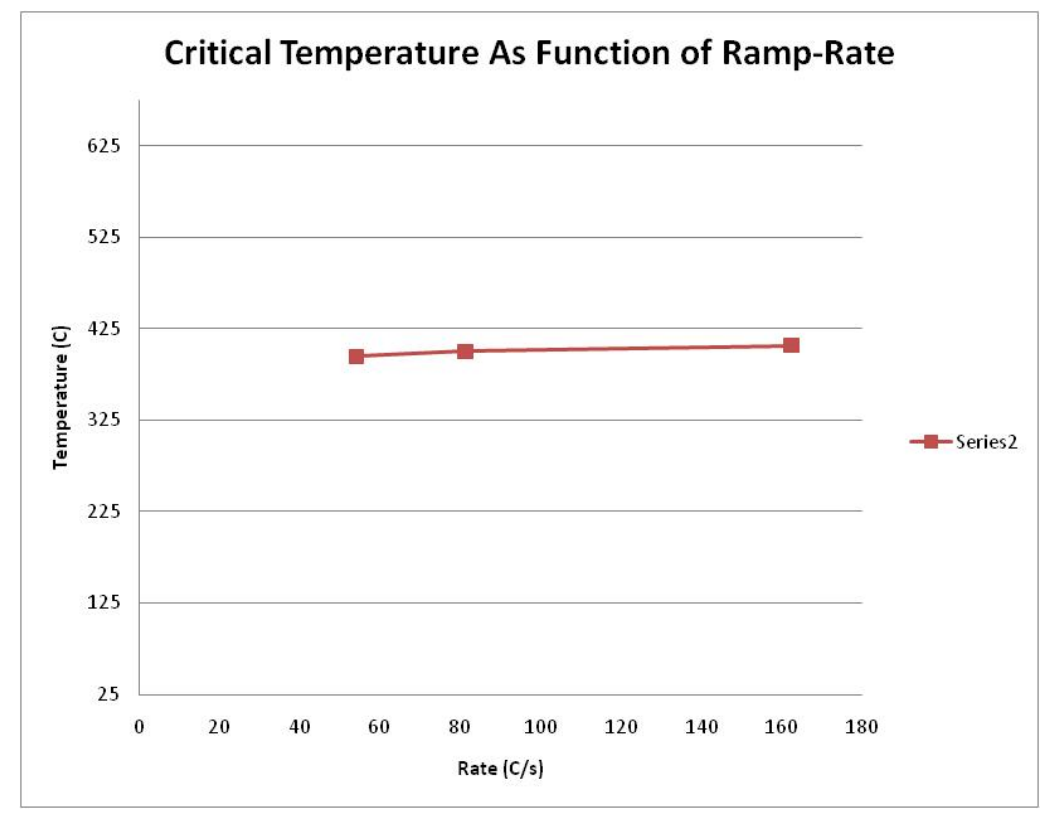

Figure 2 Critical temperature versus ramp rate

\section{Experimental Design}

\section{Target Canister}

A cylindrical target canister, shown in side view in Fig. 3, was designed and fabricated. The canister's replaceable target plate facilitates testing of various materials and thicknesses. Irradiation by the diode laser array is indicted in Fig. 3. by the red arrows. The 1- $\mathrm{mm}$ thick, 316 stainless steel canister was sized with 3" diameter and length of 4" to accommodate propellant fills up to $400 \mathrm{gm}$, although only $200 \mathrm{gm}$ was used in this study. Thus a Teflon spacer, indicated by the yellow rectangle in Fig. 3, was inserted to compress the propellant against the target plate. 


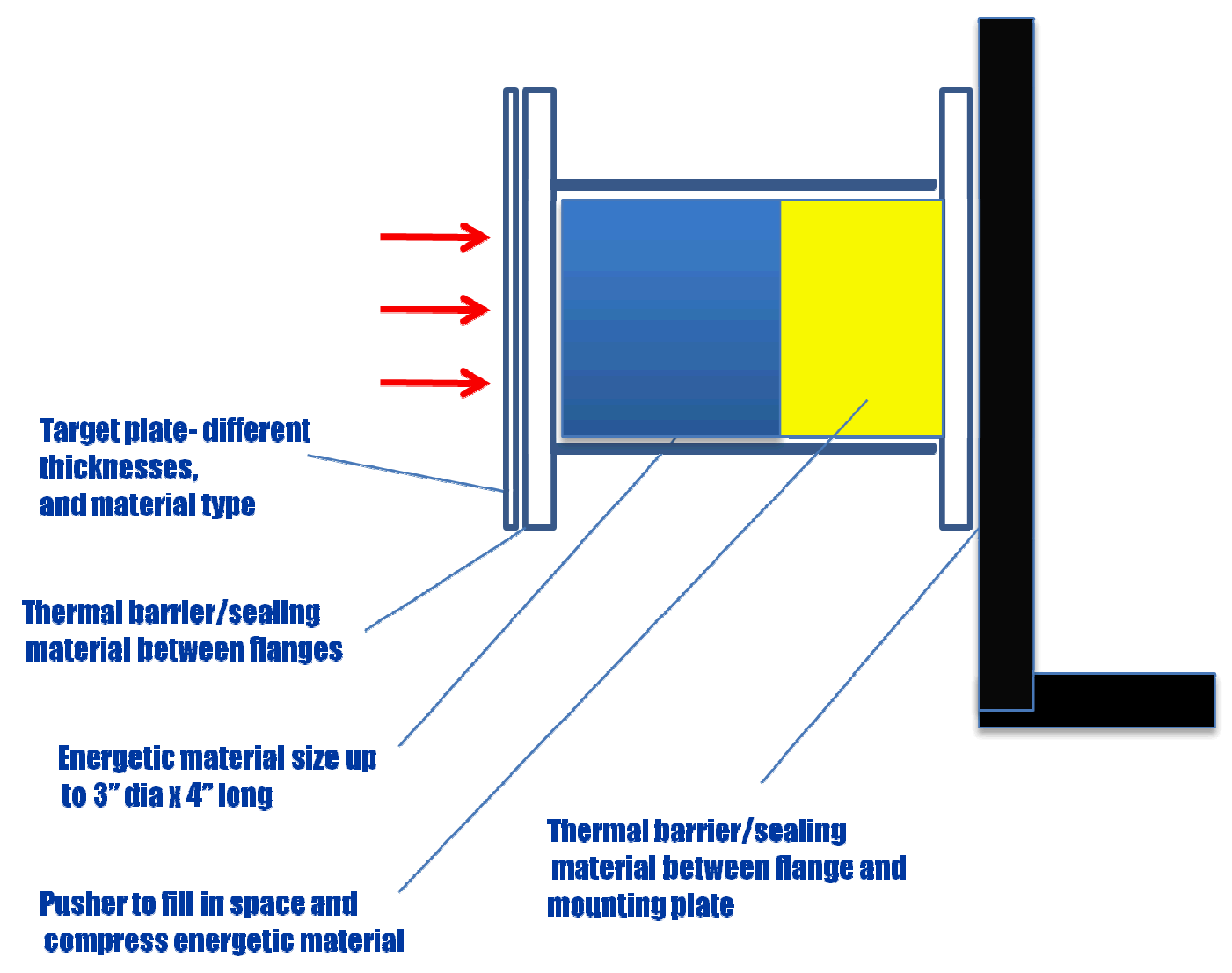

Figure 3. Schematic of target canister in side view

A 1-mm thick, 316 stainless steel target was used because steel retains most of its room-temperature tensile strength at the predicted $400 \mathrm{C}$ ignition temperature of the AP propellant, as shown in Fig. 4. Thus the canister was expected to confine the burning propellant sufficiently to produce an explosive deflagration, whereas a target plate of high-strength aluminum would not, as indicated also by Fig. 4 .

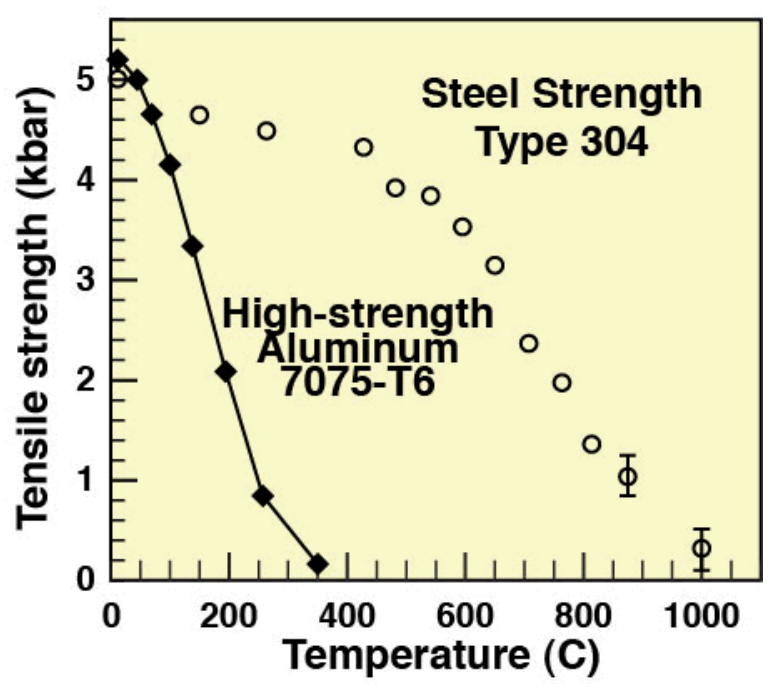


Figure 4. Tensile strength versus temperature for 304 stainless steel and high-strength aluminum 7075T6

The canister components, target plate and thermocouples used to record temperatures both inside and outside the canister are shown in Fig. 5, along with photographs of the assembled canister, showing the Teflon spacer and pressure transducer installed in the back plate, and a photograph of the canister filled with the $200 \mathrm{gm}$ of granular AP propellant.
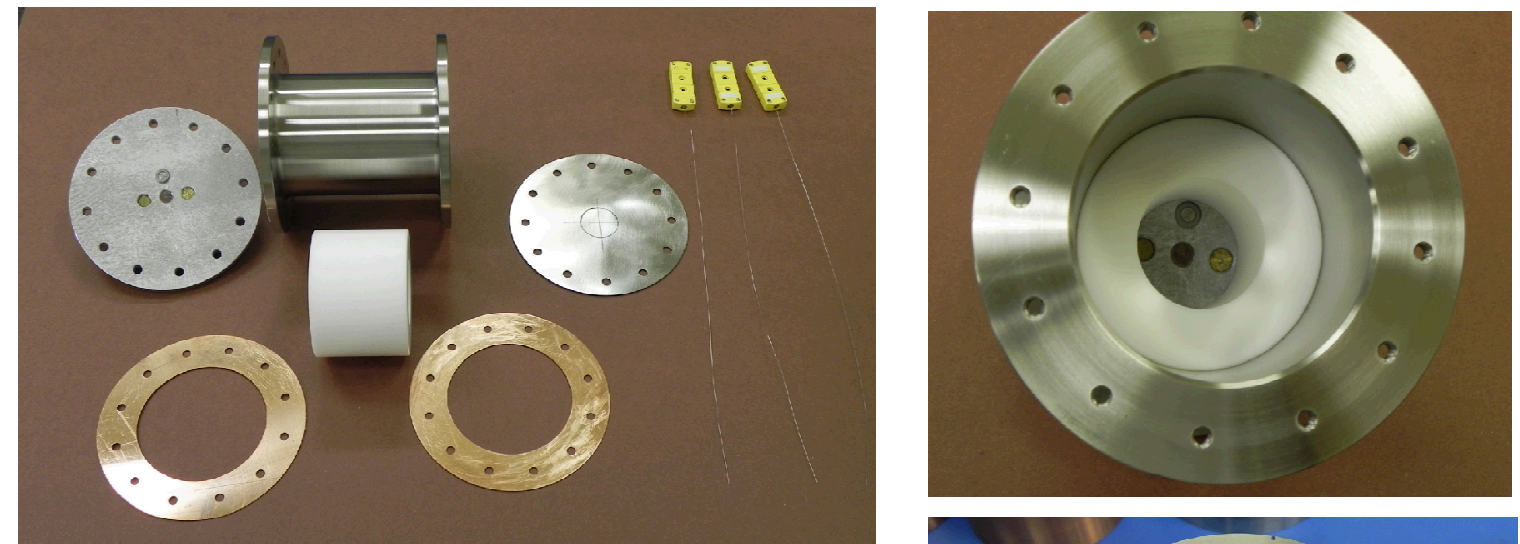

Canister components and 1-mm thick 316 SS target plate

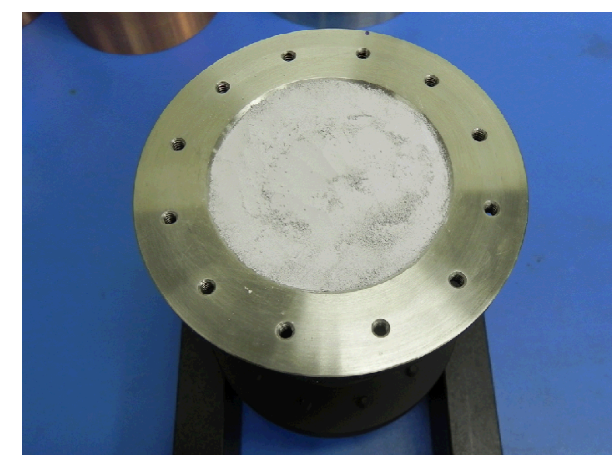

Figure 5. Canister components, interior of assembled canister showing Teflon spacer and pressure transducer, and granular AP propellant fill.

Fig. 6 shows the assembled canister, with three thermocouples attached to the outside of the target plate at its center and at 1" and 2" from center. Three thermocouples also were located inside the canister at the same radial positions. 


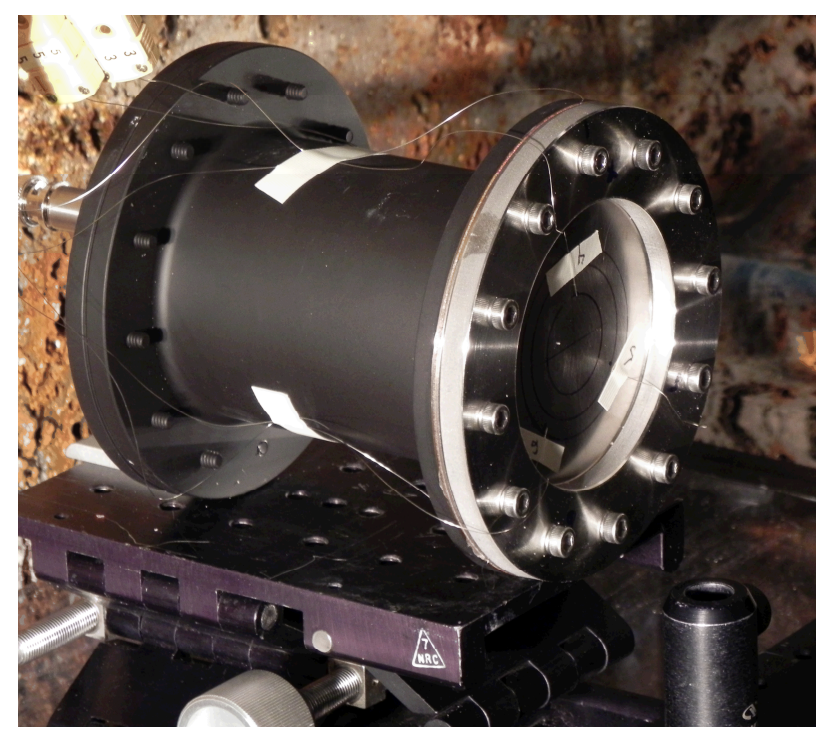

Figure 6. Assembled target canister with thermocouples attached at target plate center and at 1" and 2" from center

\section{Diode Laser Array and Light Transport System}

To achieve the necessary temperature and ramp rates as determined by pre-shot modeling required a diode laser array capable of delivering radiation intensity on the surface of the target plate of approximately $100 \mathrm{~W} / \mathrm{cm}^{2}$. This intensity could be achieved using available 10-bar, 400-W diode-laser arrays in the multiplex arrangement shown schematically in Fig. 7. Emission from the arrays was polarized thus allowing combining in pairs using thin film polarizers to produce two beam lines, which then were focused and spatially overlapped on the target surface to produce the requiredradiation intensity over a $3 \times 3 \mathrm{~cm}^{2}$ spot.

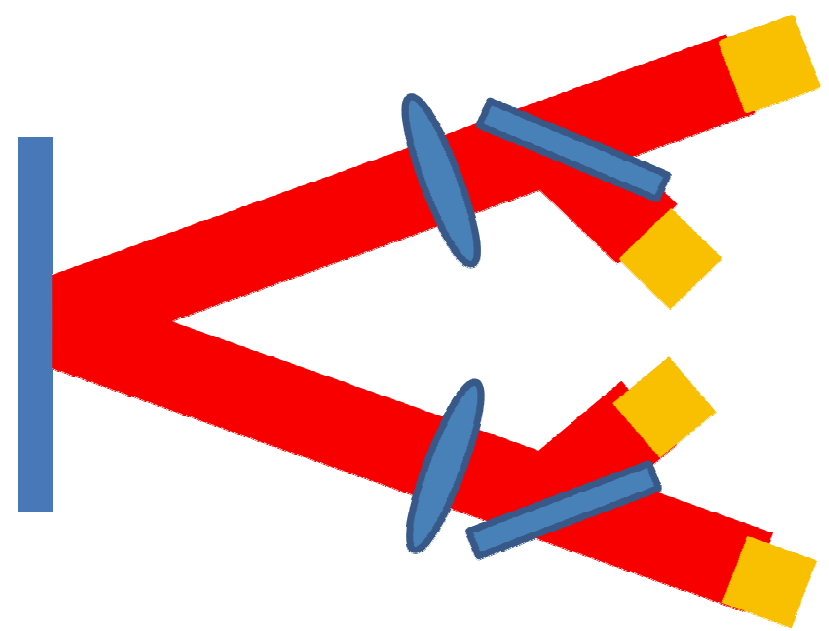

Figure 7. Diode laser array multiplex schematic. Individual 10-bar, 400-W arrays are polarization combined and spatially overlapped on the target plate.

The final spatial intensity profile of the four overlapped arrays is shown in Figure 8. 


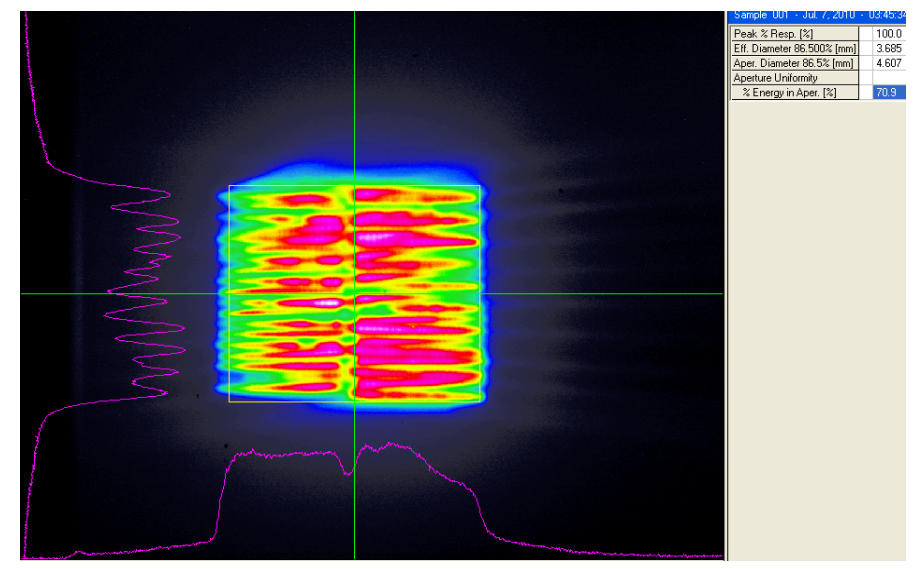

Figure 8. Intensity distribution of four combined diodelaser arrays over $3 \times 3 \mathrm{~cm}^{2}$ spot at target plate

The diode arrays and transport optics were installed on a 24 " $\times 18^{\prime \prime}$ aluminum plate as shown in Fig. 9. In pre-shot testing, these four multiplexed arrays heated a 1-mm thick 316 stainless steel plate to $650 \mathrm{C}$ in 4 seconds thus demonstrating significant margin to reach the predicted ignition temperature of $400 \mathrm{C}$. The entire assembly weighed $50 \mathrm{lbs}$ and was thus easily transportable to HEAF for experiments in the explosives firing tank.

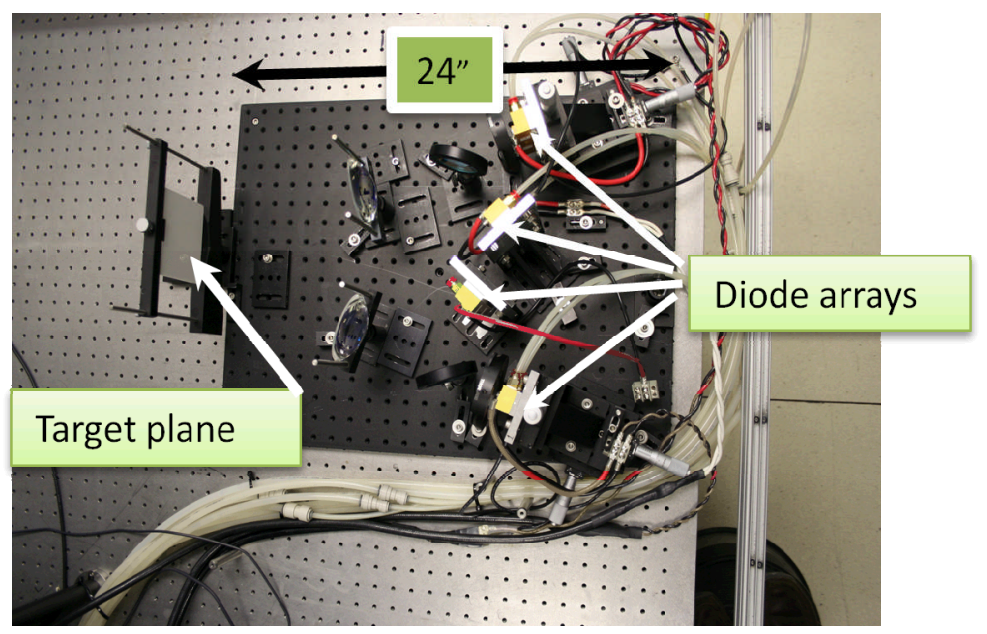

Figure 9. Top view of multiplexed diode arrays and light delivery optics

\section{Experiment}

The diode array assembly and the target canister were placed in aprotective blast shield inside the 1-kg firing tank at HEAF as shown in Fig. 10. The electrical power system for the diode arrays wasinstalled outside the firing tank while the diode array cooling system, consisting of a water chiller, reservoir, and pumps, was located inside the tank to improve cooling of the diode arrays needed to achieve maximum power delivery to the target canister. The six thermocouples and pressure transducer were connected to recording instruments outside the firing tank. Time evolution of the laser target interaction was recorded by two video cameras operating at standard video frame rates, one with a side view of the canister and the other with a top view. These cameras were used to record overall aspects of the laser 
target interaction. In addition, a high-speed video camera with a framing rate of 1000 frames per second was also used to record the interaction with greater temporal resolution.

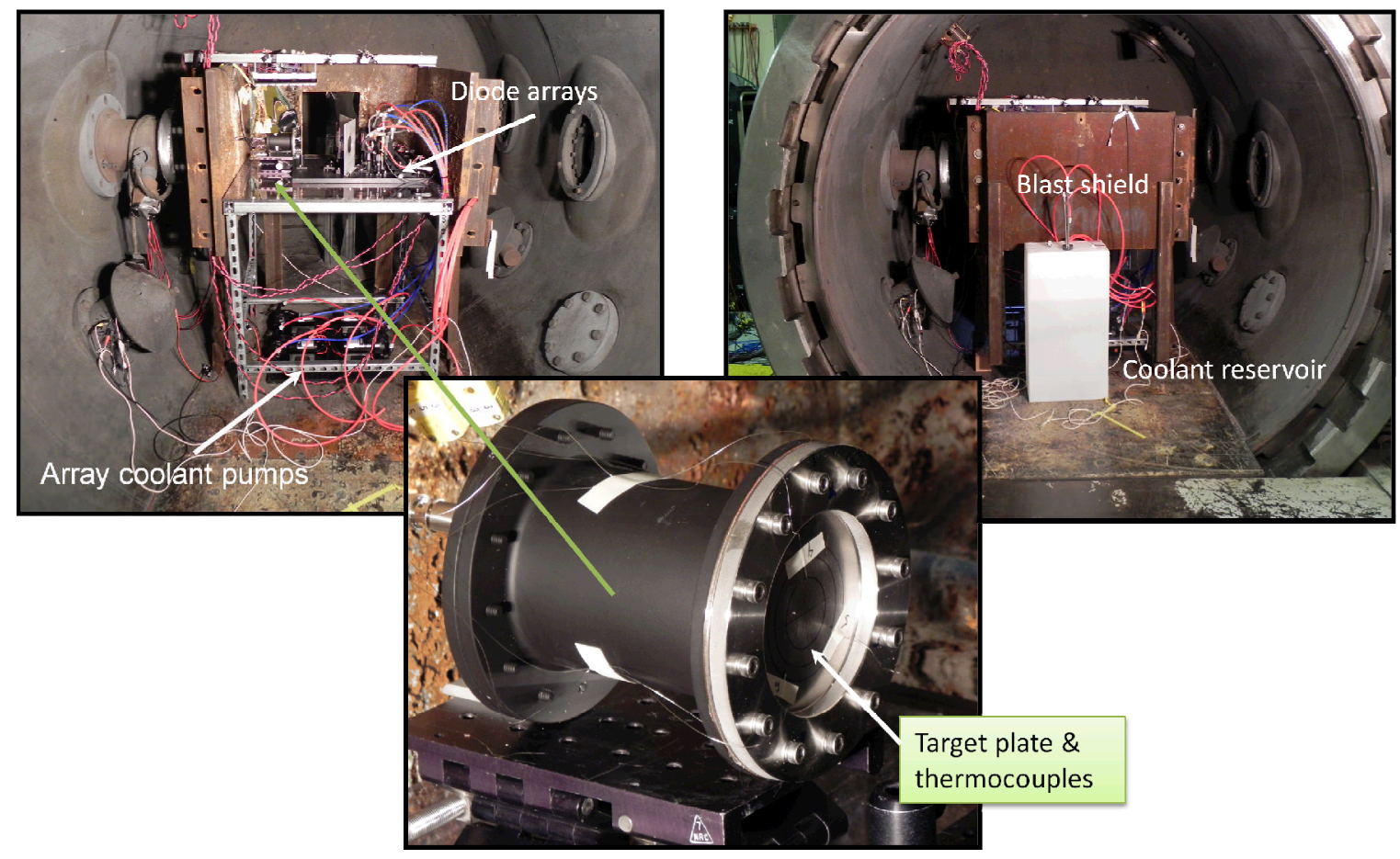

Figure 10. Target canister and diode laser array installed with protective blast shield inside the 1-kg firing tank at HEAF

Proper functioning of the laser and diagnostic equipment was verified before starting the experiment. All equipment functioned properly and the laser-target interaction event was successfully recorded.

\section{Experimental Results -}

The observed laser-target interaction is best described as a two-stage cookoff. Unfortunately the video camera recordings of the complete event cannot be shown here so the two-stage cookoff must instead be described by reference to select video frames. Radiation from the diode array initially heats the target plate, producing the visible glow shown in Fig. 11 (a). The first stage of the laser cookoff occurs when the temperature of the propellant at the inside surface of thetarget plate reaches approximately $400 \mathrm{C}$. At that point, the propellant ignites, releasing heat that begins to soften the target plate. Rising internal pressure from the gas released by the burning propellantcauses formation of a small hole in the target plate through which burning propellant is ejected, as shown in Fig.11(b). The second-stage cookoff occurs as the remaining propellant continues to burn with an expanding burn front, thus increasing the pressure in the canister. As shown in Fig. 12, this increasing pressure causes the burn rate to increase, which further increases the pressure. This positive feedback causes a violent, runaway deflagration as indicated by the high-speed video camera frames shown in Fig. 13. 


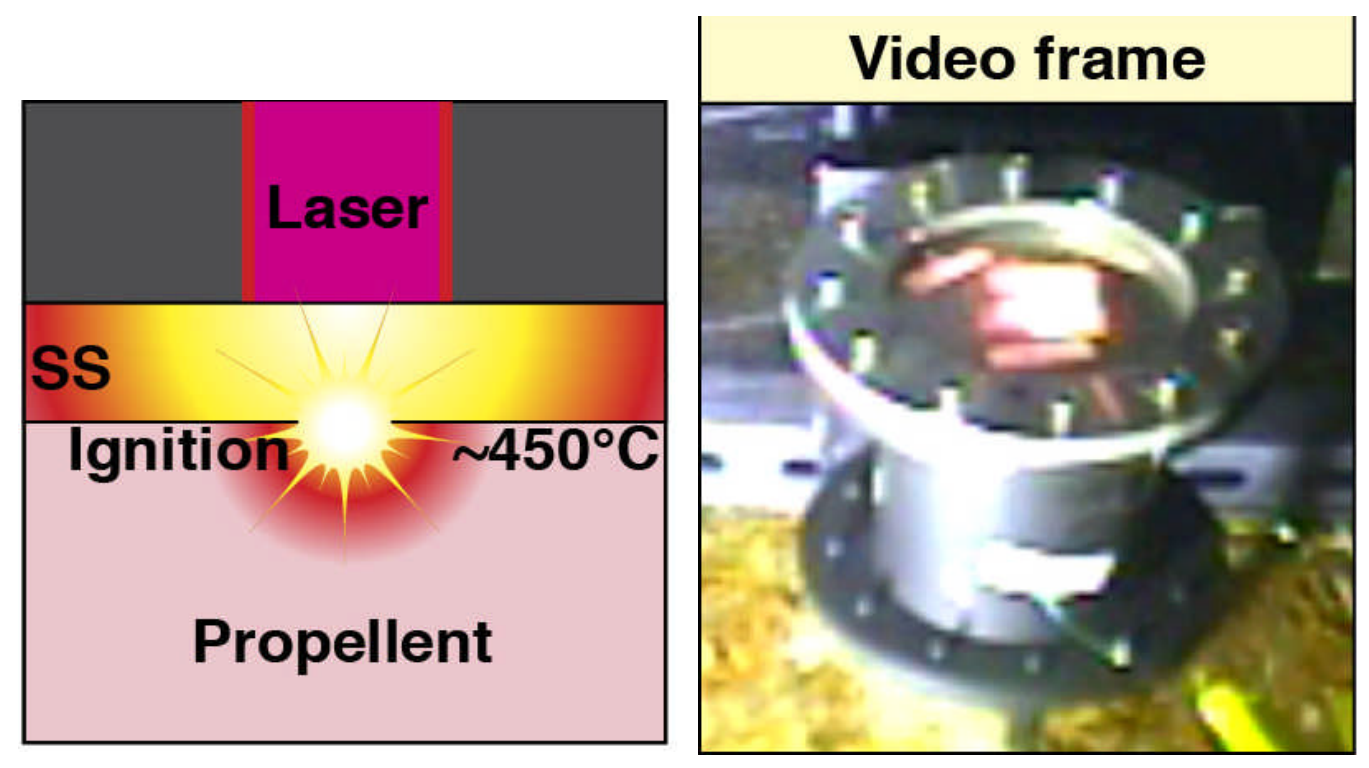

Figure 11(a). Laser heating to ignition

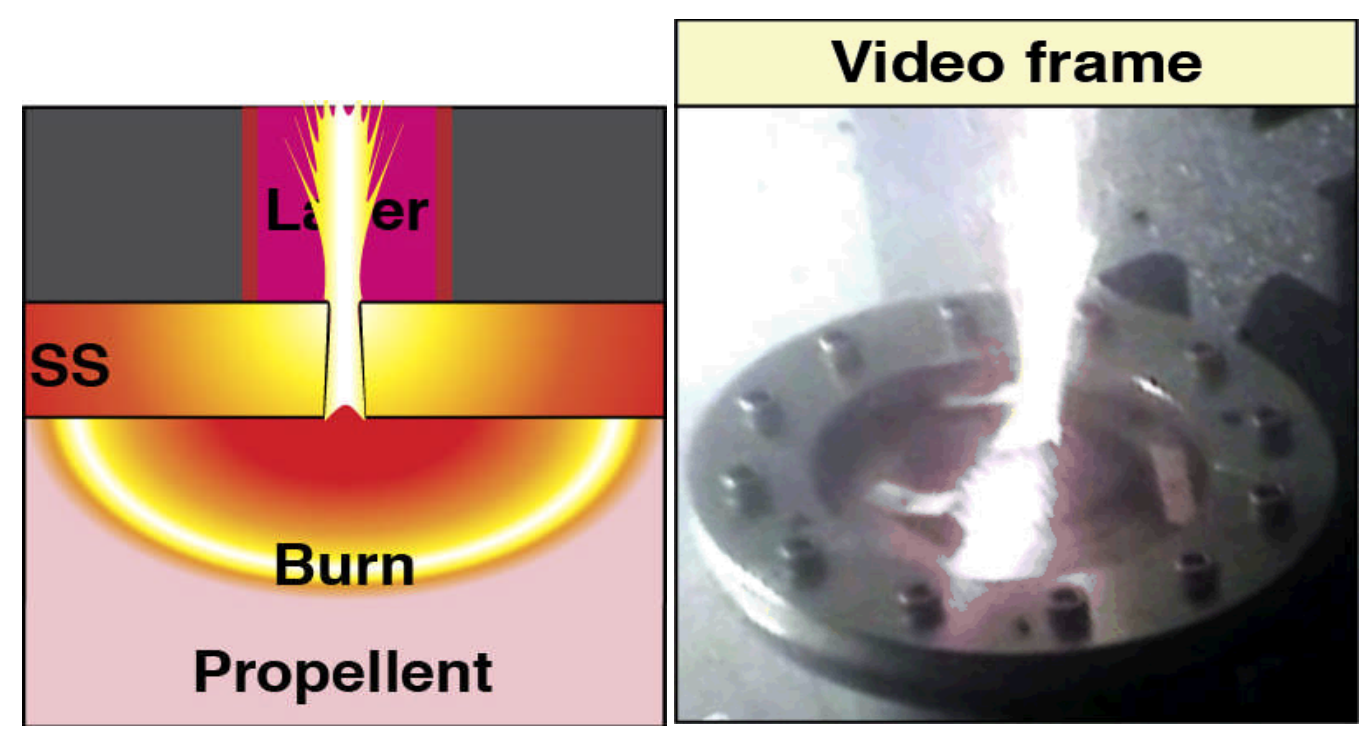

Figure 11(b). Stage 1 cookoff - Initial hole formation 


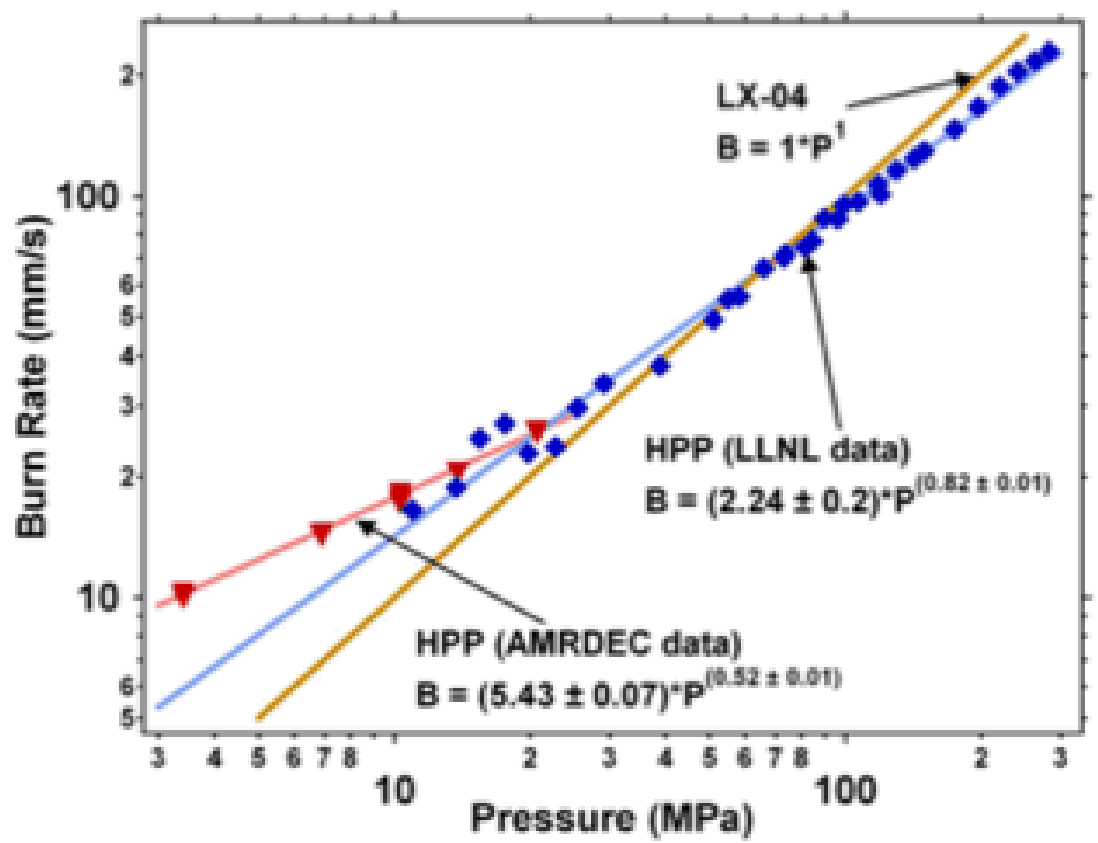

Figure 12. Propellant burn rate versus pressure

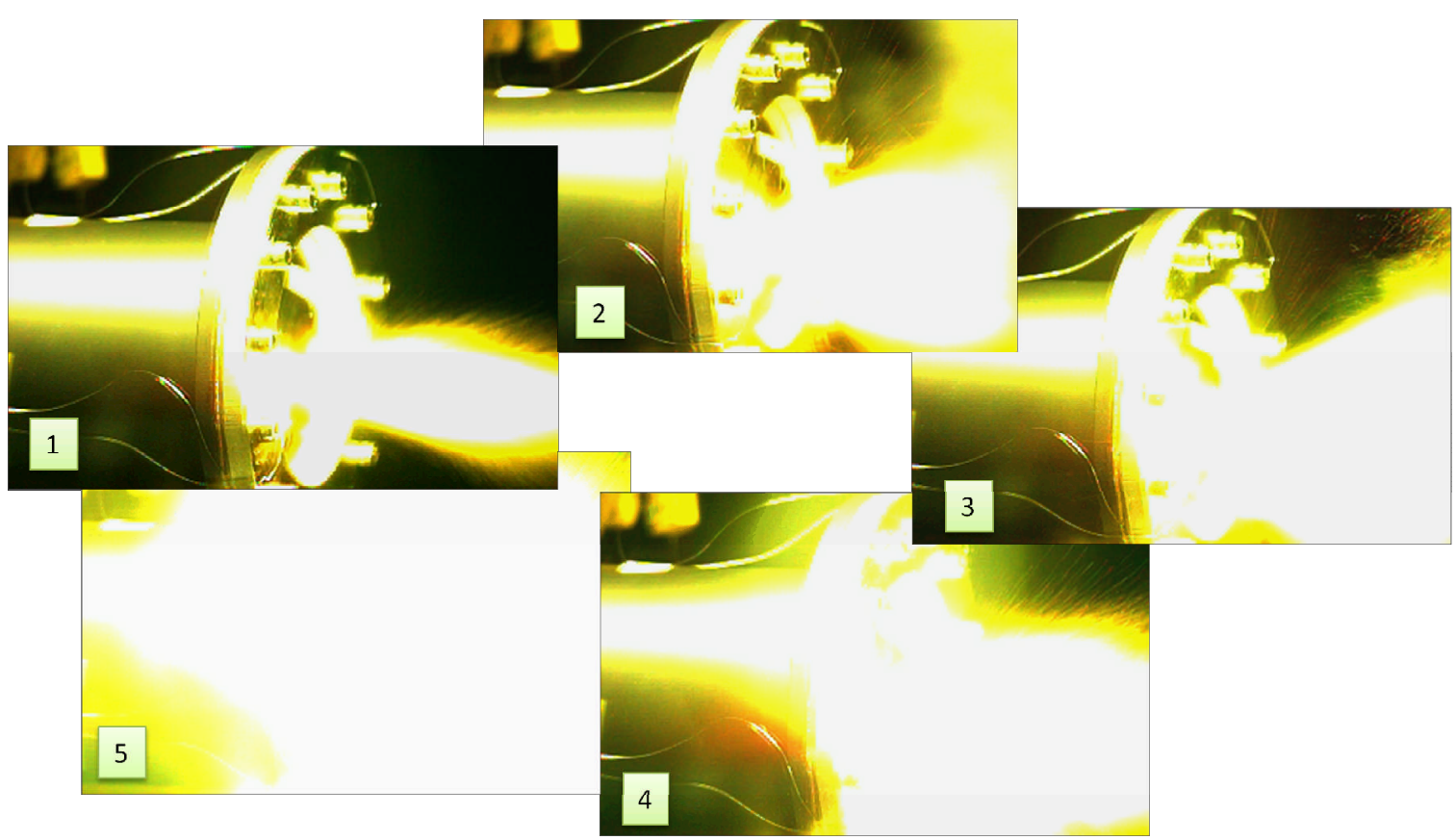

Figure 13. Stage 2 Cookoff - Runaway deflagration producing violent explosion-like event (1000 frame/s. video images) 
The post-shot photos of the target canister in Fig. 14 show a petal-like fracture morphology of the target plate with evidence of ductile fracture. Energy released by the cookoff was sufficient to launch the canister upward to the ceiling of the firing tank at high speed.
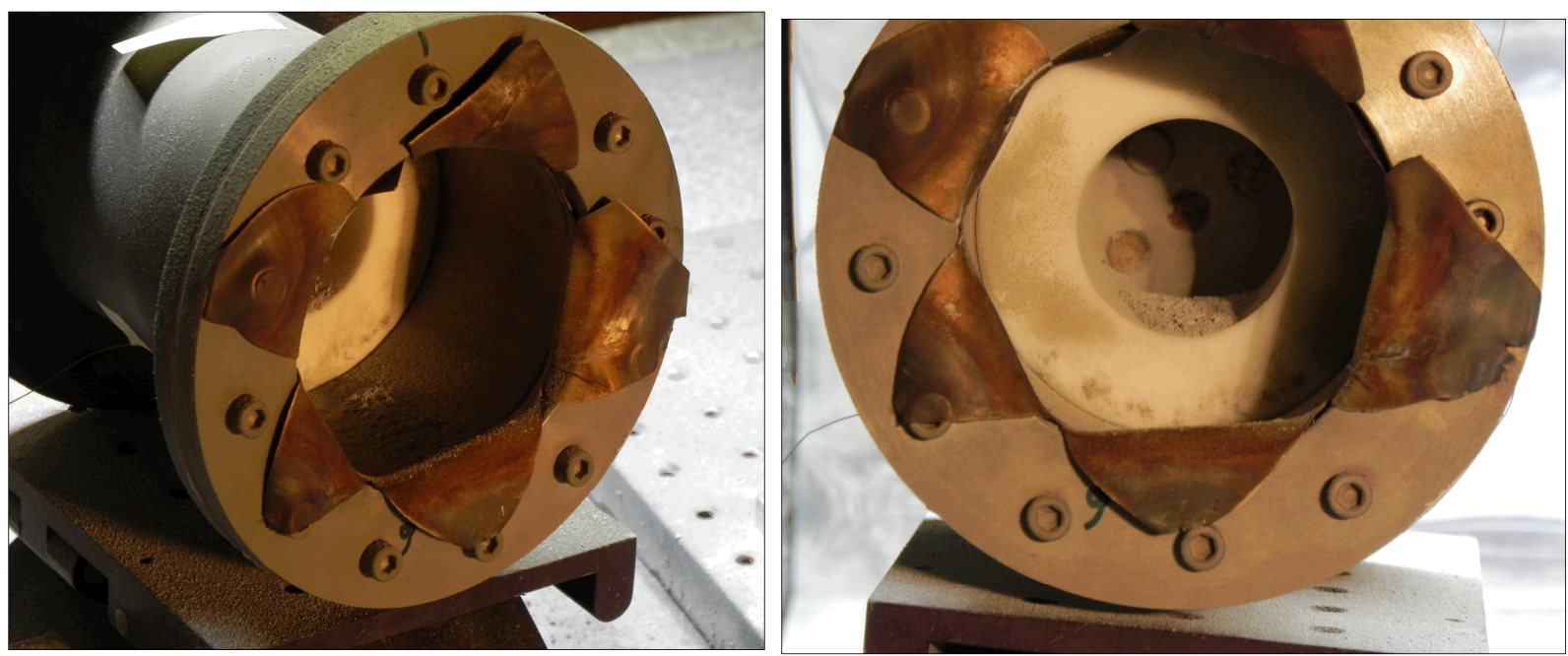

Figure 14. Post-shot photos of target canister, with petal morphology showing evidence of ductile fracture.

Data from the six thermocouples and the pressure transducer is shown in Fig. 15. Temperatures recorded by the thermocouples inside the canister at the target plate center and at 1 " and 2" from center are shown as the red, yellow, and light green traces respectively, and from thermocouples at the same radial positions outside the canister are the dark green, blue and purple traces. Pressure recorded by the transducer located just inside the canister's back plate is shown as the black trace, although unfortunately the transducer did not have sufficient dynamic range to provide useful information. 


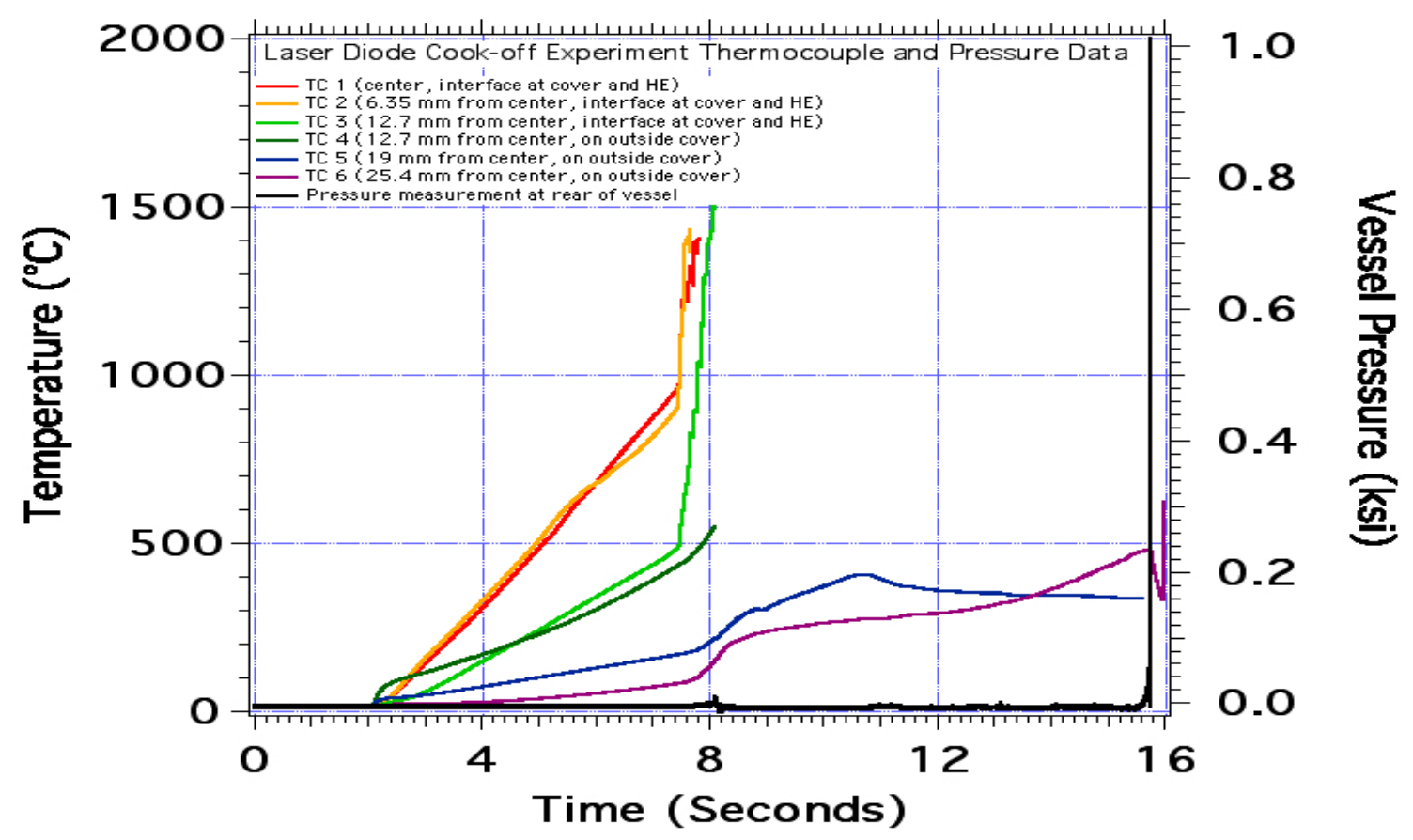

Figure 15. Temperature recorded at three radii inside (red, yellow, light green) and outside (dark green, blue, purple) target plate and pressure (black) recorded at canister rear center

\section{Post-shot Modeling}

Preliminary simulation of Stage 1 of the observed laser cookoff event has been performed using a twodimensional axi-symmetric mechanical/thermal/chemical model. Results obtained to date are summarized in Fig. 16, which represents the laser-target interaction at three times, (a) initiation of laser irradiation begins, (b) ignition of the propellant, and (c) the Stage-1 hole formation. Each of the three frames represents the target canister in cross section, with laser heating applied to the target plate on the left side. Color coding of the top portion of each frame represents the propellant status: pink representing unburned and red burned propellant. Coloring of lower portion represents the local pressure as indicated by the color code located in the lower left of the figure. Even this initial modeling effort clearly reproduces, at least qualitatively, the Stage-1 hole formation observed in the experiment. Simulation of the Stage- 2 explosive deflagration will require a more extensive three-dimensional modeling effort, which although beyond the resources of this project, we hope to be able to complete in the near future. 

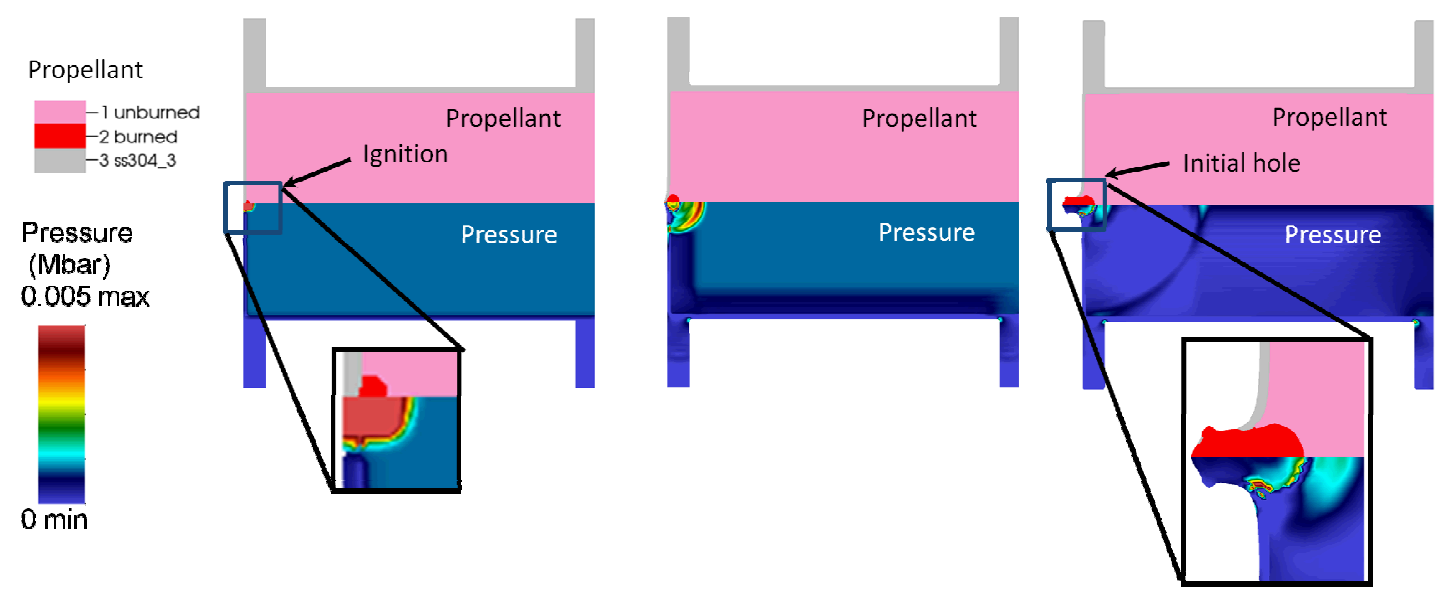

Figure 16. Results of 2D axi-symmetric model of Stage-1 cookoff

\section{Conclusion}

Successful demonstration of the feasibility of performing high power laser-target interaction experiments using low cost, easily transportable laser diode arrays will serve as a launch point for follow-on programs within the DoD. Such programs offer a low cost option to what are today prohibitively expensive field tests done with actual or near full-scale targets and fielded high power laser systems. This activity will contribute to maintaining LLNL's technical vitality and world dominance in the field of high performance multi-physics simulation, and enhance the Laboratory's ability to address future "Work for Others" missions within DoD.

\section{Acknowledgements}

This Feasibility Study was a joint effort by NIF \& PSA and HEAF, with contributions of key ideas and advice from many people in both organizations. We acknowledge in particular S. Mitchell, K. Cutter and K. Kanz, for design, construction and operation of the diode laser array and target canister; K. Vandersall, F. Garcia, and D. Greenwood for propellant, diagnostics and experimental operations at HEAF; and G. Bonanno and J. Maienschein for support on the project concept, personnel, equipment and facilities.

\section{References}

1. R. J. Beach, W. J. Benett, B. L. Freitas, D. Mundinger, B. J. Comaskey, R. W. Solarz, M. A. Emanuel, "Modular microchannel cooled heatsinks for high average power laser diode arrays," IEEE J. Quantum Electron. 28, 966-975, 1992.

2. J.A. Skidmore, B.L. Freitas, J. Crawford, J. Santariano, E. Utterback, L. DiMercurio, K. Cutter, and S. Sutton, "Silicon monolitiic microchannel-cooled laser diode array", Appl. Phys. Lett. 77, 10-12, 2000.

3. P.C. Hsu, M. Dehaven, G. Hurst, "Thermal Ignition Study of HPP”, LLNL Internal Report, Oct. 14,2009 